\title{
The Effect of Myopenia on the Inflammatory Response Early after Colorectal Surgery
}

Citation for published version (APA):

Smeets, B. J. J., Brinkman, D. J., Horsten, E. C. J., Langius, J. A. E., Rutten, H. J. T., de Jonge, W. J., \& Luyer, M. D. P. (2018). The Effect of Myopenia on the Inflammatory Response Early after Colorectal Surgery. Nutrition and Cancer-An International Journal, 70(3), 460-466.

https://doi.org/10.1080/01635581.2018.1445763

Document status and date:

Published: 01/01/2018

DOI:

10.1080/01635581.2018.1445763

Document Version:

Publisher's PDF, also known as Version of record

Document license:

Taverne

Please check the document version of this publication:

- A submitted manuscript is the version of the article upon submission and before peer-review. There can be important differences between the submitted version and the official published version of record.

People interested in the research are advised to contact the author for the final version of the publication, or visit the DOI to the publisher's website.

- The final author version and the galley proof are versions of the publication after peer review.

- The final published version features the final layout of the paper including the volume, issue and page numbers.

Link to publication

\footnotetext{
General rights rights.

- You may freely distribute the URL identifying the publication in the public portal. please follow below link for the End User Agreement:

www.umlib.nl/taverne-license

Take down policy

If you believe that this document breaches copyright please contact us at:

repository@maastrichtuniversity.nl

providing details and we will investigate your claim.
}

Copyright and moral rights for the publications made accessible in the public portal are retained by the authors and/or other copyright owners and it is a condition of accessing publications that users recognise and abide by the legal requirements associated with these

- Users may download and print one copy of any publication from the public portal for the purpose of private study or research.

- You may not further distribute the material or use it for any profit-making activity or commercial gain

If the publication is distributed under the terms of Article $25 \mathrm{fa}$ of the Dutch Copyright Act, indicated by the "Taverne" license above, 


\section{The Effect of Myopenia on the Inflammatory Response Early after Colorectal Surgery}

Boudewijn J. J. Smeets, David J. Brinkman, Eelco C. J. Horsten, Jacqueline A. E. Langius, Harm J. T. Rutten, Wouter J. de Jonge \& Misha D. P. Luyer

To cite this article: Boudewijn J. J. Smeets, David J. Brinkman, Eelco C. J. Horsten, Jacqueline A. E. Langius, Harm J. T. Rutten, Wouter J. de Jonge \& Misha D. P. Luyer (2018) The Effect of Myopenia on the Inflammatory Response Early after Colorectal Surgery, Nutrition and Cancer, 70:3, 460-466, DOI: 10.1080/01635581.2018.1445763

To link to this article: https://doi.org/10.1080/01635581.2018.1445763

曲 Published online: 14 Mar 2018.

Submit your article to this journal

山 Article views: 116

Q View related articles ¿

View Crossmark data $₫$ 


\title{
The Effect of Myopenia on the Inflammatory Response Early after Colorectal Surgery
}

\author{
Boudewijn J. J. Smeets ${ }^{\mathrm{a}, \mathrm{b}}$, David J. Brinkman ${ }^{\mathrm{a}, \mathrm{c}}$, Eelco C. J. Horsten ${ }^{\mathrm{a}}$, Jacqueline A. E. Langius ${ }^{\mathrm{d}, \mathrm{e}}$, \\ Harm J. T. Rutten (iD ${ }^{a, b}$, Wouter J. de Jonge ${ }^{c}$, and Misha D. P. Luyer (D) ${ }^{a}$ \\ ${ }^{\mathrm{a} D e p a r t m e n t}$ of Surgery, Catharina Hospital Eindhoven, Eindhoven, The Netherlands; ${ }^{\mathrm{b}} \mathrm{GROW}$ School for Oncology and Developmental Biology, \\ Maastricht University, Maastricht, The Netherlands; 'Tytgat Institute for Intestinal and Liver Research, Academic Medical Center, Amsterdam, The \\ Netherlands; ${ }^{\mathrm{d}}$ Department of Nutrition and Dietetics, Internal Medicine, VU University Medical Centre, Amsterdam, The Netherlands; ${ }^{\mathrm{e}}$ Faculty of \\ Health, Nutrition and Sport, The Hague University of Applied Sciences, The Hague, The Netherlands
}

\begin{abstract}
Background: Myopenia (low skeletal muscle mass) is associated with an increased risk of complications following colorectal surgery, however, the underlying mechanism is poorly understood. This study investigates the effect of myopenia on the early postoperative systemic inflammatory response. Materials and methods: In 78 patients undergoing colorectal surgery, the presence of myopenia was preoperatively assessed using computed tomography images of the third lumbar vertebra. Interleukin-8 (IL-8) and soluble tumor necrosis factor receptor-1 (TNFRSF1A) were measured in plasma before and $4 \mathrm{~h}$ after start of surgery as part of a randomized controlled trial investigating the effect of perioperative gum chewing on the inflammatory response. Multivariable linear regression analysis was performed to assess the effect of myopenia on inflammatory markers while correcting for possible confounders. Results: Four hours after start of surgery, IL-8 was higher in patients with myopenia than in patients without myopenia (352 \pm 268 vs. $239 \pm 211 \mathrm{pg} / \mathrm{ml}, P=0.048$ ), while TNFRSF1A was similar between groups. After adjusting for sex and the intervention with perioperative gum chewing, myopenia remained associated with higher postoperative IL-8 concentrations $(P=0.047)$. Conclusion: Myopenia may affect IL-8 early after colorectal surgery. However, more studies are needed to validate these findings.
\end{abstract}

\section{ARTICLE HISTORY}

Received 24 March 2017

Accepted 5 December 2017

\section{Introduction}

Myopenia indicates the clinically relevant loss of skeletal muscle mass, and is common in patients with colorectal cancer $(1,2)$. Myopenia is considered an indicator of increased vulnerability to stressors, and is associated with higher complication rates following colorectal surgery (3-6). Although dietary- and exercise-based strategies may improve skeletal muscle mass to some extent after some time, these interventions are not always feasible in patients with colorectal cancer requiring prompt surgical treatment (7-10). Therefore, rather than by increasing skeletal muscle mass, postoperative complications in patients with myopenia may be reduced more effectively by interventions that target the underlying biological mechanisms that impair postoperative recovery. However, these biological mechanisms are poorly understood. To develop effective interventions in the surgical population, it is necessary to understand how myopenia increases the risk of postoperative complications.
Multiple studies have demonstrated that myopenia is associated with an increased inflammatory response before and several days after colorectal surgery (11-14). However, the effect of myopenia on the early (i.e., within hours) postoperative systemic inflammatory response is unclear. Recent studies suggest that the magnitude of the early systemic inflammatory response to surgery is related to the development of postoperative complications (15-20). In this light, examining the effect of myopenia on the early postoperative inflammatory response may help explain the increased risk of complications. In this study, the effects of myopenia on the early postoperative systemic inflammatory response and complications are investigated in patients undergoing colorectal surgery.

\section{Materials and Methods}

\section{Study Characteristics}

This study was performed with data from a previous randomized controlled clinical trial that compared

CONTACT Boudewijn J.J. Smeets boudewijn.smeets@catharinaziekenhuis.nl E Department of Surgery, Catharina Hospital Eindhoven, Michelangelolaan 2, 5623, EJ Eindhoven, The Netherlands. 
perioperative gum chewing to placebo in patients undergoing major colorectal surgery in two large Dutch tertiary referral hospitals (21). All outcomes except presence of myopenia were predefined in the original study protocol (22), which was designed in accordance with the Declaration of Helsinki and Good Clinical Practice and was approved by the Medical Ethics Committee of Catharina Hospital Eindhoven.

\section{Patient Population}

Patients were included if aged $18 \mathrm{yr}$ or older and undergoing elective, open colorectal surgery. Patients were excluded if they suffered from peritoneal carcinomatosis, inflammatory bowel disease, a history of gastric or esophageal surgery, a disturbance of acetylcholine metabolism owing to neurological disease or depression, preexisting ileostoma, allergy to mint, or if they used agents influencing gut motility (including opioids) or acetylcholine metabolism (e.g., parasympatheticomimetics).

A total of 120 patients were previously included and randomized to the intervention group or the control group (21). The intervention group was instructed to chew gum starting $3 \mathrm{~h}$ before surgery, and again starting $3 \mathrm{~h}$ after surgery until start of oral intake. Alternatively, the control group received a placebo dermal patch at the same moments as the intervention group and was instructed not to chew gum (21).

In the current study, we excluded patients who did not have a preoperative computed tomography (CT) scan suitable for myopenia assessment.

\section{Analysis of Skeletal Muscle Mass}

The presence of myopenia was determined by two trained, independent researchers (BS and $\mathrm{EH}$ ) by means of preoperative CT image analysis, while blinded for treatment allocation and postoperative outcomes (23). A CT scan was deemed suitable for skeletal muscle analysis if it was performed within 2 mo prior to surgery and if none of the following conditions were present: abnormal muscular anatomy (e.g., stoma, abdominal wall hernia), poor demarcation between different body compartments, presence of artefacts, or incomplete visualization of the abdominal wall musculature.

CT image analysis was performed using Slice-O-Matic V5.0 software (Tomovision, Montreal, Canada) as previously described.(23) Briefly, total surface area of skeletal muscle was determined on a single image at the level of the third lumbar vertebra (L3) using Hounsfield Unit thresholds of -29-150 for skeletal muscle. Skeletal muscle surface area was normalized for height in meters squared $\left(\mathrm{m}^{2}\right)$ and reported as lumbar skeletal muscle index $\left(\mathrm{cm}^{2} / \mathrm{m}^{2}\right)$. The presence of myopenia was determined in accordance with body mass index- and sex-specific threshold values as defined by Martin et al. (24).

\section{Measurement of Inflammatory Markers and Postoperative Complications}

Venous blood samples were collected before surgery and $4 \mathrm{~h}$ after start of surgery to measure interleukin 8 (IL-8) and soluble tumor necrosis factor receptor 1 (TNFRSF1A) as specific markers of the innate systemic inflammatory response. TNFRSF1A is a transmembrane receptor through which tumor necrosis factor (TNF)- $\alpha$ exerts its effects, and gives a good representation of TNF- $\alpha$ plasma concentrations (25). EDTA-treated plasma was separated by centrifugation and stored at $-80^{\circ} \mathrm{C}$ within 30 min until further analysis. Plasma concentrations of inflammatory markers were determined in plasma samples with an enzyme-linked immunosorbent assay (Hycult Biotech, Uden, The Netherlands). Furthermore, first postoperative C-reactive protein (CRP) levels were determined in plasma by means of an immunoturbodimetric assay (Roche/Hitachi cobas c system, Roche, Mannheim, Germany) as a part of routine clinical care on postoperative day 1,2 , or 3 .

All postoperative complications were registered prospectively until patient discharge, and were graded according to the Clavien-Dindo classification (26).

\section{Statistical Analysis}

SPSS v22.0 (IBM, Armonk, New York, USA) was used for statistical analysis. Continuous parameters are presented as mean \pm standard deviation or median [interquartile range], and compared between patients with and without myopenia using the unpaired $t$-test or Mann-Whitney $U$ test as appropriate. Categorical variables were compared between groups using the $\chi^{2}$ test or the Fisher's exact test. The association between myopenia and inflammatory markers was analyzed by means of univariable and multivariable linear regression analysis. In addition to perioperative gum chewing, other potential confounding factors were identified by comparing relevant baseline characteristics between patients with vs. without myopenia, and between patients in whom the postoperative inflammatory response was smaller vs. greater than the overall median value. To minimize the risk of bias, adjustments were made for gum chewing and for other potential confounding factors significantly associated with any inflammatory marker in multivariable linear regression analysis. Statistical significance was determined as $P<0.05$. 


\section{Results}

\section{Patient Characteristics}

Out of 120 patients included in the original trial, 8 patients were excluded after randomization, due to consent withdrawal $(n=4)$ and technical reasons $(n=4)$. No preoperative CT scan was available in 24 patients, and in 10 patients the CT scan was performed more than 2 mo prior to surgery. Subsequently, a total of 78 patients were included in the current study. Overall, patients had a mean skeletal muscle index of $46.6 \pm 9.0 \mathrm{~cm}^{2} / \mathrm{m}^{2}$. Myopenia was present in 31 patients $(40 \%)$. Patients with myopenia were more often female $(P=0.012)$, and were more likely to have a higher American Society of Anesthesiologists (ASA) grade $(\mathrm{P}=0.035)$ when compared to patients without myopenia (Table 1). No other differences in patient characteristics or surgical details were observed between patients with vs. without myopenia.

\section{Inflammatory Markers and Complications in Patients With vs. Without Myopenia}

At baseline, four patients with myopenia had detectable concentrations of IL-8, while IL- 8 was not detectable in patients without myopenia. This resulted in significant higher preoperative concentrations of IL-8 in patients with myopenia compared to patients without myopenia $(P=$ 0.011) (Table 2). Baseline concentrations of TNFRSF1A were similar between groups $(P=0.176)$.

Surgery induced a marked inflammatory response in all patients regardless of presence of myopenia. However,
Table 2. Inflammatory parameters at baseline and $4 \mathrm{~h}$ after start of surgery in myopenia vs. no myopenia.

\begin{tabular}{|c|c|c|c|}
\hline & Myopenia $(N=31)$ & No myopenia $(N=47)$ & $P$ value \\
\hline \multicolumn{4}{|l|}{ Baseline } \\
\hline IL-8 (pg/ml) $)^{\mathrm{a}}$ & $0[0-6.01]$ & $0[0-0]$ & 0.011 \\
\hline TNFRSF1A $(\mathrm{ng} / \mathrm{ml})^{\mathrm{b}}$ & $0.54[0.28-1.19]$ & $0.45[0.25-1.36]$ & 0.176 \\
\hline \multicolumn{4}{|l|}{ After surgery } \\
\hline $\mathrm{IL}-8(\mathrm{pg} / \mathrm{ml})^{\mathrm{c}}$ & $352 \pm 268$ & $239 \pm 211$ & 0.048 \\
\hline TNFRSF1A $(\mathrm{ng} / \mathrm{ml})^{\mathrm{b}}$ & $0.83[0.29-2.98]$ & $0.78[0.29-1.85]$ & 0.296 \\
\hline $\mathrm{CRP}(\mathrm{mg} / \mathrm{l})^{\mathrm{b}}$ & 160 [110-270] & $153[90-255]$ & 0.636 \\
\hline
\end{tabular}

CRP, first measured C-reactive protein; IL-8, interleukin-8; TNFRSF1A, soluble tumor necrosis factor receptor 1 .

Values are ${ }^{\mathrm{a}}$ median [range] or ${ }^{\mathrm{b}}$ median [interquartile range] or ${ }^{\mathrm{c}}$ mean $\pm \mathrm{s.d}$.

postoperative IL-8 was significantly higher in patients with myopenia compared to patients without myopenia $(P=$ 0.048). Postoperative TNFRSF1A was similar between groups $(P=0.296)$. First postoperative CRP concentrations were similar between patients with and without myopenia $(P=0.636)$.

Myopenia was not associated with an increased risk of any postoperative complication in this patient cohort.

\section{Identification of Confounders}

Sex and ASA grade were identified as potential confounders for the postoperative inflammatory response based on differences in baseline characteristics between patients with vs. without myopenia. Next, patients were stratified based on the magnitude of the postoperative inflammatory response, i.e., smaller vs. greater than the overall median postoperative concentration of IL-8 (259

Table 1. Baseline characteristics of patients with vs. without myopenia.

\begin{tabular}{|c|c|c|c|}
\hline & Myopenia $(N=31)$ & No myopenia $(N=47)$ & $P$ value \\
\hline Age (years) & $69 \pm 12$ & $64 \pm 9$ & 0.058 \\
\hline Sex ratio (M:F) & $16: 15$ & $37: 10$ & 0.012 \\
\hline Height $(\mathrm{cm})$ & $172 \pm 11$ & $172 \pm 8$ & 0.853 \\
\hline Weight (kg) & 72 [64-83] & $78[73-84]$ & 0.077 \\
\hline Body mass index $\left(\mathrm{kg} / \mathrm{m}^{2}\right)$ & $25[23-28]$ & 25 [24-29] & 0.189 \\
\hline ASA grade & & & 0.035 \\
\hline 1 & $2(6)$ & $11(23)$ & \\
\hline 2 & $25(81)$ & $35(75)$ & \\
\hline 3 & $4(13)$ & $1(2)$ & \\
\hline Previous abdominal surgery & $7(23)$ & $10(21)$ & 0.891 \\
\hline Diabetes mellitus & $8(27)$ & $8(17)$ & 0.625 \\
\hline Smoking & $5(27)$ & $4(50)$ & 0.233 \\
\hline Duration of surgery (min) & 123 [110-205] & $130[110-180]$ & 0.959 \\
\hline Blood loss (ml) & $500[240-1000]$ & $300[150-725]$ & 0.238 \\
\hline Colostomy required & $14(45)$ & $21(45)$ & 0.967 \\
\hline Type of operation & & & 0.245 \\
\hline Right hemicolectomy & $12(39)$ & $10(21)$ & \\
\hline Left hemicolectomy & $9(29)$ & $18(39)$ & \\
\hline Rectal resection & $10(32)$ & $19(40)$ & \\
\hline Gum chewing: Control & $16: 15$ & $20: 27$ & 0.432 \\
\hline Skeletal muscle index $\left(\mathrm{cm}^{2} / \mathrm{m}^{2}\right)$ & $37.7[35.3-40.8]$ & $52.2[46.0-55.9]$ & $<0.001$ \\
\hline
\end{tabular}

ASA, American Society of Anesthesiologists.

Values are numbers (\%) or mean \pm s.d. or median [interquartile range]. 
Table 3A. Baseline characteristics in patients with a low $(<260$ $\mathrm{pg} / \mathrm{ml}$ ) vs. high ( $\geq 260 \mathrm{pg} / \mathrm{ml}$ ) postoperative IL-8 response.

\begin{tabular}{lccc}
\hline & Low IL-8 & High IL-8 & $P$ value \\
\hline Body mass index $\left(\mathrm{kg} / \mathrm{m}^{2}\right)$ & $25[24-28]$ & $26[24-28]$ & 0.547 \\
Duration of surgery $(\mathrm{min})$ & $120[101-178]$ & $154[117-221]$ & 0.050 \\
Blood loss (ml) & $300[100-800]$ & $500[300-900]$ & 0.101 \\
Type of surgery & & & 0.629 \\
$\quad$ Colon & $23(64)$ & $21(58)$ & \\
Rectum & $13(36)$ & $15(42)$ & \\
\hline
\end{tabular}

IL-8, interleukin 8.

Values are numbers (\%) or median [interquartile range].

$\mathrm{pg} / \mathrm{ml})$, TNFRSF1A (0.79 $\mathrm{ng} / \mathrm{ml})$, and CRP (156 mg/l), and relevant baseline characteristics were compared between groups (Tables 3A-C). There was a trend toward a longer duration of surgery in patients with a higher IL-8 response, however, this was not statistically significant. Body mass index was greater in patients with a high postoperative CRP concentration $(P=0.046)$. Intraoperative blood loss and type of resection (colon vs.

Table 3B. Baseline characteristics in patients with a low $(<0.79$ $\mathrm{pg} / \mathrm{ml}$ ) vs. high ( $\geq 0.79 \mathrm{pg} / \mathrm{ml}$ ) postoperative TNFRSF1A response.

\begin{tabular}{lccc}
\hline & Low TNFRSF1A & High TNFRSF1A & $P$ value \\
\hline Body mass index $\left(\mathrm{kg} / \mathrm{m}^{2}\right)$ & $25[24-28]$ & $26[24-29]$ & 0.723 \\
Duration of surgery $(\mathrm{min})$ & $128[102-190]$ & $142[111-192]$ & 0.313 \\
Blood loss $(\mathrm{ml})$ & $300[175-750]$ & $500[100-900]$ & 0.665 \\
Type of surgery & & 0.851 & \\
Colon & $21(60)$ & $23(62)$ & \\
Rectum & $14(40)$ & $14(38)$ & \\
\hline
\end{tabular}

TNFRSF1A, soluble tumor necrosis factor receptor 1 .

Values are numbers (\%) or median [interquartile range].

Table 3C. Baseline characteristics in patients with a low $(<156 \mathrm{mg} / \mathrm{l})$ vs. high $(\geq 156 \mathrm{mg} / \mathrm{l})$ postoperative CRP response.

\begin{tabular}{lccc}
\hline & Low CRP & High CRP & $P$ value \\
\hline Body mass index $\left(\mathrm{kg} / \mathrm{m}^{2}\right)$ & $25[24-27]$ & $27[24-28]$ & 0.046 \\
Duration of surgery $(\mathrm{min})$ & $123[104-173]$ & $148[112-211]$ & 0.119 \\
Blood loss (ml) & $400[250-840]$ & $300[100-900]$ & 0.579 \\
Type of surgery & & & 0.929 \\
$\quad$ Colon & $23(62)$ & $24(63)$ & \\
$\quad$ Rectum & $14(38)$ & $14(37)$ & \\
\hline
\end{tabular}

CRP, first measured C-reactive protein.

Values are numbers (\%) or median [interquartile range]. rectum) were similar in all groups. Based on these findings, body mass index was evaluated as a potential confounder in linear regression analysis.

\section{Linear Regression Analysis}

In univariable linear regression analysis, myopenia was associated with increased concentrations of IL-8 at baseline $(P=0.040)$ and $4 \mathrm{~h}$ after start of surgery $(P=$ 0.048) (Table 4).

In addition to perioperative gum chewing, sex, ASA grade, and body mass index were evaluated as potential confounding factors for the association between myopenia and inflammatory markers. Perioperative gum chewing was associated with lower concentrations of IL-8 $4 \mathrm{~h}$ after start of surgery $(\mathrm{P}=0.048)$. Female sex was associated with increased concentrations of TNFRSF1A at baseline $(P=0.041)$. Body mass index and ASA grade were not significantly associated with any inflammatory marker in univariable linear regression analysis.

Due to the significant association with inflammatory markers in univariable linear regression analysis, perioperative gum chewing and sex were added as confounders in multivariable linear regression analysis. After adjusting for the effect of perioperative gum chewing and sex, myopenia remained associated with increased concentrations of IL-8 $4 \mathrm{~h}$ after start of surgery $(P=0.047)$.

When the four patients that demonstrated detectable IL-8 concentrations at baseline were excluded from multivariable linear regression analysis, the association between myopenia and postoperative IL- 8 concentrations was no longer significant $(B=84.183,95 \%$ CI $-33.673-202.039, P=0.158)$.

\section{Discussion}

The current study demonstrates no association between myopenia and postoperative concentrations of TNFRSF1A or CRP. Myopenia may be associated with increased

Table 4. Linear regression analyses between myopenia and inflammatory parameters.

\begin{tabular}{|c|c|c|c|c|c|c|}
\hline & \multicolumn{3}{|c|}{ Crude model } & \multicolumn{3}{|c|}{ Adjusted model $^{\mathrm{a}}$} \\
\hline & $B$ & $95 \% \mathrm{Cl}$ & $P$ value & $B$ & $95 \% \mathrm{Cl}$ & $P$ value \\
\hline \multicolumn{7}{|l|}{ Baseline } \\
\hline IL-8 & 0.481 & $0.22-0.941$ & 0.040 & 0.503 & $0.021-0.986$ & 0.041 \\
\hline TNFRSF1A & 0.074 & $-0.49-0.198$ & 0.233 & 0.052 & $-0.072-0.176$ & 0.406 \\
\hline \multicolumn{7}{|l|}{ After surgery } \\
\hline IL-8 & 113.780 & $1.070-226.490$ & 0.048 & 116.328 & $1.470-231.186$ & 0.047 \\
\hline TNFRSF1A & 0.142 & $-0.61-0.344$ & 0.167 & 0.127 & $-0.860-0.340$ & 0.238 \\
\hline CRP & 10.001 & $-31.132-51.135$ & 0.629 & 10.539 & $-32.386-53.464$ & 0.626 \\
\hline
\end{tabular}

CRP, first measured C-reactive protein; IL-8, interleukin-8; TNFRSF1A, soluble tumor necrosis factor receptor 1.

${ }^{a}$ Adjusted for perioperative gum chewing and sex. 
postoperative concentrations of IL-8. However, this association is limited by the presence of confounders.

Previous studies investigating the relation between myopenia and inflammation mainly focused on the preoperative inflammatory response. Before surgery, myopenia was associated with increased markers of subclinical inflammation, including the neutrophilto-lymphocyte ratio (NLR) and the modified Glasgow Prognostic Score (mGPS) $(12,13)$. In patients with colorectal cancer, increased NLR- and mGPS-scores before surgery were associated with higher mortality rates and more infective complications $(27-30)$. It is hypothesized that a preoperative state of increased inflammation, as seen in patients with myopenia, impairs wound healing and alters the inflammatory response to surgery (31-33).

The findings of the current study may support the hypothesis that myopenia alters the postoperative inflammatory response, as the presence of reduced skeletal muscle mass was associated with increased IL- 8 concentrations early after surgery. However, no effect was observed on TNFRSF1A or CRP. IL-8 is produced early in the inflammatory cascade mainly by monocytes and macrophages following activation by TNF- $\alpha$ (34). IL- 8 then induces chemotaxis and activation of neutrophils, that subsequently secrete other inflammatory mediators including calprotectin (35). Interestingly, Reisinger et al. found that reduced skeletal muscle mass in patients undergoing colorectal surgery was associated with higher calprotectin concentrations on postoperative days 2-5, while no effect was seen on IL-6 or CRP (14). Taken together, we hypothesize that myopenia may augment the IL-8 response early after start of surgery, which subsequently leads to an increase of other, but not all, inflammatory markers (e.g., calprotectin) in a later stage. Postoperative measurements of IL-8 concentrations at later timepoints could provide more insight in this matter. However, in the original trial IL-8 was determined only before and $4 \mathrm{~h}$ after surgery.

It is well established that postoperative complications induce a marked inflammatory response. Vice versa, an increased early inflammatory response to surgery is associated with the development of complications later (15-20). Specifically, an upregulated innate, systemic inflammatory response can suppress the acquired, cellmediated immunity of the host, which increases the risk of infective complications and may also promote tumor progression $(19,36)$. Furthermore, the early postoperative local and systemic inflammatory response is essential in the development of postoperative ileus, which is a major contributor to postoperative morbidity (16). Taken together, an augmented early postoperative inflammatory response may explain the increased risk of complications in patients with myopenia as seen in other studies (3-6).

In contrast to other studies that clearly demonstrate an increase in complications in patients with the reduced skeletal muscle mass (3-6), in this study myopenia was not associated with an effect on postoperative complications. These differences may be explained by several limitations in the current study. First, myopenia was assessed in a retrospective manner. This reduced the number of patients suitable for analysis resulting in a relatively small patient group when compared to other studies (3-6). Second, we applied thresholds of myopenia that were adjusted for sex and body mass index as proposed by Martin et al. (24). However, specific thresholds to determine clinically relevant loss of skeletal muscle mass vary throughout the literature, which limits comparison of our results with other studies (3). Third, several confounders were identified that may have affected the effect of myopenia on inflammatory markers. However, our data and other literature $(37,38)$ do not support a strong effect of sex or ASA grade on the postoperative inflammatory response. The surgical approach (open vs. laparoscopic), setting (acute vs. elective), and degree of surgical trauma may also affect the magnitude of the surgical inflammatory response $(39,40)$. However, in our study cohort only elective, open surgery was performed, and no significant differences were observed in amount of blood loss, or the duration or type of surgery between patients with vs. without myopenia, or between patients with a limited vs. substantiated inflammatory response. Furthermore, multivariable linear regression analysis was performed to adjust for the effects of potential confounders. Fourth, when excluding patients with detectable concentrations of IL- 8 at baseline, the association between myopenia and postoperative IL- 8 concentrations was no longer significant. As such, an elevated preoperative inflammatory state may be a confounder for postoperative IL- 8 concentrations. Alternatively, the smaller cohort size may have decreased statistical power.

Several strategies have been explored to prevent or reverse skeletal muscle wasting, including physical exercise, dietary supplements, and certain pharmacological agents $(7,8,10,41)$. However, most pharmaceutical agents are associated with limited effects on muscle mass and serious side-effects $(7,10,42)$. Physical exercise in combination with adequate nutrition is deemed most effective in increasing skeletal muscle mass after some time, but is not always feasible in patients with colorectal cancer requiring prompt surgical treatment $(7,10)$. Instead, a short intervention that targets the underlying biological effects of myopenia may be more effective to counter the increased risk of postoperative complications. In this light, the anti-inflammatory effect of perioperative gum 
chewing (21) may be interesting; however, more research is needed to validate our findings and to determine to what degree inflammation plays a role in the development of complications in patients with myopenia.

In conclusion, myopenia was not associated with the postoperative concentrations of CRP of TNFRSF1A, while it may affect plasma concentrations of IL-8 early after colorectal surgery. However, larger studies are needed to determine the true effect of myopenia on the postoperative inflammatory response given the presence of possible confounders and small sample size of our study cohort.

\section{Conflict of Interest}

The current study was performed at Catharina Hospital Eindhoven, Eindhoven, The Netherlands and Orbis Medical Center, Sittard, The Netherlands. This manuscript has not been published elsewhere and has not been submitted simultaneously for publication elsewhere.

\section{Funding}

The current study was enabled via home institution funds of the Department of Surgery, Catharina Hospital, Eindhoven, The Netherlands.

\section{ORCID}

Harm J. T. Rutten (D) http://orcid.org/0000-0003-2532-950X Misha D. P. Luyer iD http://orcid.org/0000-0002-9483-1520

\section{References}

1. Broughman JR, Williams GR, Deal AM, Yu H, Nyrop KA, et al.: Prevalence of sarcopenia in older patients with colorectal cancer. J Geriatr Oncol 6, 442-445, 2015. doi:10. 1016/j.jgo.2015.08.005.

2. Fearon K, Evans WJ, and Anker SD: Myopenia-a new universal term for muscle wasting. J Cachexia Sarcopenia Muscle 2, 1-3, 2011. doi:10.1007/s13539-011-0025-7.

3. Malietzis G, Aziz O, Bagnall NM, Johns N, Fearon KC, et al.: The role of body composition evaluation by computerized tomography in determining colorectal cancer treatment outcomes: A systematic review. Eur J Surg Oncol 41, 186-196, 2015. doi:10.1016/j.ejso.2014.10.056.

4. Lieffers JR, Bathe OF, Fassbender K, Winget M, and Baracos VE: Sarcopenia is associated with postoperative infection and delayed recovery from colorectal cancer resection surgery. Br J Cancer 107, 931-936, 2012. doi:10. 1038/bjc.2012.350.

5. Miyamoto Y, Baba Y, Sakamoto Y, Ohuchi M, Tokunaga $\mathrm{R}$, et al.: Sarcopenia is a negative prognostic factor after curative resection of colorectal cancer. Ann Surg Oncol 22, 2663-2668, 2015. doi:10.1245/s10434-014-4281-6.

6. Margadant CC, Bruns ER, Sloothaak DA, van Duijvendijk $\mathrm{P}$, van Raamt AF, et al.: Lower muscle density is associated with major postoperative complications in older patients after surgery for colorectal cancer. Eur J Surg Oncol 42, 1654-1659, 2016. doi:10.1016/j.ejso.2016.05.040.

7. Rolland Y, Onder G, Morley JE, Gillette-Guyonet S, Abellan van Kan G, et al.: Current and future pharmacologic treatment of sarcopenia. Clin Geriatr Med 27, 423-447, 2011. doi:10.1016/j.cger.2011.03.008.

8. Beyer I, Mets T, and Bautmans I: Chronic low-grade inflammation and age-related sarcopenia. Curr Opin Clin Nutr Metab Care 15, 12-22, 2012. doi:10.1097/MCO. 0b013e32834dd297.

9. Sinclair M, Gow PJ, Grossmann M, and Angus PW: Review article: Sarcopenia in cirrhosis-aetiology, implications and potential therapeutic interventions. Aliment Pharmacol Ther 43, 765-777, 2016. doi:10.1111/ apt.13549.

10. Wakabayashi $\mathrm{H}$, and Sakuma K: Comprehensive approach to sarcopenia treatment. Curr Clin Pharmacol 9, 171-180, 2014. doi:10.2174/1574884708666131111192845.

11. Meng SJ, and Yu LJ: Oxidative stress, molecular inflammation and sarcopenia. Int J Mol Sci 11, 1509-1526, 2010. doi:10.3390/ijms11041509.

12. Malietzis G, Johns N, Al-Hassi HO, Knight SC, Kennedy $\mathrm{RH}$, et al:: Low muscularity and myosteatosis is related to the host systemic inflammatory response in patients undergoing surgery for colorectal cancer. Ann Surg 263, 320-325, 2012.

13. Richards $\mathrm{CH}$, Roxburgh CS, MacMillan MT, Isswiasi S, Robertson EG, et al.: The relationships between body composition and the systemic inflammatory response in patients with primary operable colorectal cancer. PLoS One 7, e41883, 2012. doi:10.1371/journal.pone.0041883.

14. Reisinger KW, Derikx JP, van Vugt JL, Von Meyenfeldt MF, Hulsewe KW, et al.: Sarcopenia is associated with an increased inflammatory response to surgery in colorectal cancer. Clin Nutr 35, 924-927, 2016.

15. Rettig TC, Verwijmeren L, Dijkstra IM, Boerma D, van de Garde EM, et al.: Postoperative interleukin-6 level and early detection of complications after elective major abdominal surgery. Ann Surg 263, 1207-1212, 2016.

16. Peters EG, De Jonge WJ, Smeets BJ, and Luyer MD: The contribution of mast cells to postoperative ileus in experimental and clinical studies. Neurogastroenterol Motil 27, 743-749, 2015. doi:10.1111/nmo.12579.

17. McSorley ST, Horgan PG, and McMillan DC: The impact of preoperative corticosteroids on the systemic inflammatory response and postoperative complications following surgery for gastrointestinal cancer: A systematic review and meta-analysis. Crit Rev Oncol Hematol 101, 139-150, 2016. doi:10.1016/j.critrevonc.2016.03.011.

18. Chuang D, Paddison JS, Booth RJ, and Hill AG: Differential production of cytokines following colorectal surgery. ANZ J Surg 76, 821-824, 2006. doi:10.1111/j.14452197.2006.03877.x.

19. Marik PE, and Flemmer M: The immune response to surgery and trauma: Implications for treatment. J Trauma Acute Care Surg 73, 801-808, 2012. doi:10.1097/ TA.0b013e318265cf87.

20. Szczepanik AM, Scislo L, Scully T, Walewska E, Siedlar M, et al.: IL-6 serum levels predict postoperative morbidity in gastric cancer patients. Gastric Cancer 14, 266-273, 2011. doi:10.1007/s10120-011-0039-z. 
21. van den Heijkant TC, Costes LM, van der Lee DG, Aerts B, Osinga-de Jong $\mathrm{M}$, et al.: Randomized clinical trial of the effect of gum chewing on postoperative ileus and inflammation in colorectal surgery. Br J Surg 102, 202-211, 2015. doi:10.1002/bjs.9691.

22. Berghmans TM, Hulsewe KW, Buurman WA, and Luyer MD: Stimulation of the autonomic nervous system in colorectal surgery: A study protocol for a randomized controlled trial. Trials 13, 93, 2012. doi:10.1186/1745-6215-13-93.

23. Mourtzakis M, Prado CM, Lieffers JR, Reiman T, McCargar LJ, et al.: A practical and precise approach to quantification of body composition in cancer patients using computed tomography images acquired during routine care. Appl Physiol Nutr Metab 33, 997-1006, 2008. doi:10.1139/H08-075.

24. Martin L, Birdsell L, Macdonald N, Reiman T, Clandinin MT, et al:: Cancer cachexia in the age of obesity: Skeletal muscle depletion is a powerful prognostic factor, independent of body mass index. J Clin Oncol 31, 1539-1547, 2013. doi:10.1200/JCO.2012.45.2722.

25. Lantz M, Malik S, Slevin ML, and Olsson I: Infusion of tumor necrosis factor (TNF) causes an increase in circulating TNF-binding protein in humans. Cytokine 2, 402-406, 1990. doi:10.1016/1043-4666(90)90048-X.

26. Dindo D, Demartines N, and Clavien PA: Classification of surgical complications: A new proposal with evaluation in a cohort of 6336 patients and results of a survey. Ann Surg 240, 205-213, 2004. doi:10.1097/01.sla.0000133083.54934.ae.

27. Moyes LH, Leitch EF, McKee RF, Anderson JH, Horgan PG, et al.: Preoperative systemic inflammation predicts postoperative infectious complications in patients undergoing curative resection for colorectal cancer. $\mathrm{Br} J$ Cancer 100, 1236-1239, 2009. doi:10.1038/sj.bjc.6604997.

28. Ishizuka M, Nagata $H$, Takagi K, Horie T, and Kubota K: Inflammation-based prognostic score is a novel predictor of postoperative outcome in patients with colorectal cancer. Ann Surg 246, 1047-1051, 2007. doi:10.1097/ SLA.0b013e3181454171.

29. De Magistris L, Paquette B, Orry D, Facy O, Di Giacomo G, et al.: Preoperative inflammation increases the risk of infection after elective colorectal surgery: Results from a prospective cohort. Int J Colorectal Dis 31, 1611-1617, 2016. doi:10.1007/s00384-016-2620-8.

30. Malietzis G, Giacometti M, Kennedy RH, Athanasiou T, Aziz $\mathrm{O}$, et al.: The emerging role of neutrophil to lymphocyte ratio in determining colorectal cancer treatment outcomes: A systematic review and meta-analysis. Ann Surg Oncol 21, 3938-3946, 2014. doi:10.1245/s10434-014-3815-2.

31. Nozoe T, Matsumata T, and Sugimachi K: Preoperative elevation of serum $\mathrm{C}$-reactive protein is related to impaired immunity in patients with colorectal cancer. $A m$ J Clin Oncol 23, 263-266, 2000. doi:10.1097/00000421200006000-00011.

32. Canna K, McArdle PA, McMillan DC, McNicol AM, Smith GW, et al.: The relationship between tumour Tlymphocyte infiltration, the systemic inflammatory response and survival in patients undergoing curative resection for colorectal cancer. Br J Cancer 92, 651-654, 2005. doi:10.1038/sj.bjc.6602419.

33. Du Clos TW, and Mold C: C-reactive protein: An activator of innate immunity and a modulator of adaptive immunity. Immunol Res 30, 261-277, 2004. doi:10.1385/ IR:30:3:261.

34. Remick DG: Interleukin-8. Crit Care Med 33, S466-S467, 2005. doi:10.1097/01.CCM.0000186783.34908.18.

35. Striz I, and Trebichavsky I: Calprotectin-A pleiotropic molecule in acute and chronic inflammation. Physiol Res 53, 245-253, 2004.

36. Roxburgh CS, Horgan PG, and McMillan DC: The perioperative immune/inflammatory insult in cancer surgery: Time for intervention? Oncoimmunology 2, e27324, 2013. doi:10.4161/onci.27324.

37. Lord JM, Midwinter MJ, Chen YF, Belli A, Brohi K, et al.: The systemic immune response to trauma: An overview of pathophysiology and treatment. The Lancet 384, 14551465, 2014. doi:10.1016/S0140-6736(14)60687-5.

38. Lopez MC, Efron PA, Ozrazgat-Baslanti T, Zhang J, Cuschieri J, et al.: Sex-based differences in the genomic response, innate immunity, organ dysfunction, and clinical outcomes after severe blunt traumatic injury and hemorrhagic shock. J Trauma Acute Care Surg 81, 478-485, 2016. doi:10.1097/TA.0000000000001113.

39. Leung KL, Lai PB, Ho RL, Meng WC, Yiu RY, et al.: Systemic cytokine response after laparoscopic-assisted resection of rectosigmoid carcinoma: A prospective randomized trial. Ann Surg 231, 506-511, 2000. doi:10.1097/ 00000658-200004000-00008.

40. Catena F, Ansaloni L, Avanzolini A, Di Saverio S, D’Alessandro L, et al.: Systemic cytokine response after emergency and elective surgery for colorectal carcinoma. Int $J$ Colorectal Dis 24, 803-808, 2009. doi:10.1007/s00384-0090677-3.

41. Subramaniam K, Fallon K, Ruut T, Lane D, McKay R, et al.: Infliximab reverses inflammatory muscle wasting (sarcopenia) in Crohn's disease. Aliment Pharmacol Ther 41, 419-428, 2015. doi:10.1111/apt.13058.

42. Scheinfeld N: A comprehensive review and evaluation of the side effects of the tumor necrosis factor alpha blockers etanercept, infliximab and adalimumab. J Dermatolog Treat 15, 280-294, 2004. doi:10.1080/09546630410017275. 